\title{
Two channel immediate memory span
}

NEVILLE MORAY AND A. J. REID

DEPARTMENT OF PSYCHOLOGY, UNIVERSITY OF SHEFFIELD, ENGLAND

Lists of digits were presented dichotically to Ss who were required to recall them by typing those received by the left ear with the left hand and those received by the right ear with the right hand. The immediate memory span whether measured by the performance on either or on both of the channels combined was substantially inferior to performance where only one list was heard and the $S$ typed the response with one hand.

Moray \& Jordan (1966) recently showed that under conditions of high S-R compatibility, performance on a "split span" memory task in which three pairs of simultaneously presented digits were to be recalled was much higher than had been found by Broadbent (1954) and others (e.g., Moray, 1960). Jordan has subsequently found, in an unpublished pilot experiment, that continuous two channel performance seems to be impossible. She required Ss to print out long series of random digits which were presented in simultaneous pairs dichotically at one pair per sec, printing the left ear message with the left hand and the right ear message with the right hand. Even after several hours practice the Ss were only achieving $50 \%$ performance, suggesting that they were alternating between the two messages, not processing them simultaneously. However, there were short bursts of up to 4-5 pairs which were output simultaneously and correctly before performance returned to the $50 \%$ level. Taken with the earlier experiment this suggests that perhaps parallel handling of simultaneous messages can be achieved up to one "short-term-store-ful." Although Moray, Bates, \& Barnett (1965) found that load per channel could not be traded for number of channels, they used an incompatible input-output situation. The following experiment was therefore designed to see whether the two channel memory span was equal to the single channel span under compatible conditions.

\section{Method and Procedure}

Twelve Ss listened to lists of digits presented at 2/sec per channel by means of a Brennel Mk. $V$ tape recorder and Brown Type $\mathrm{K}$ headphones. Single channel lists were of length $5,6,7,8$, and 9 items per list. Two channel lists were of $2 \times 3,2 \times 4$, and $2 \times 5$ items. Items were the digits 0 through 9 and no item repeated in any one list. Ten lists of each length were used, and were presented in a single block before moving on to the block of another list length. Half the Ss received single channel lists before two channel lists, and the other half vice versa. The headphones were reversed for half the Ss to balance any inequalities in recordings. Both for single channel and for double channel presentation the blocks of lists were presented in the order starting from the easier (shorter) lists and going to increasingly difficult lists, so that the easier conditions functioned as practice lists for the harder ones.

Ss responded by typing their responses on a stenotype keyboard beginning as soon as the list had ended, and responding at their own pace. They were required to report the items in the correct list in the correct order. There was a short rest period between the single and double channel series of blocks of lists.

Results

The results are shown in Tables 1,2 , and 3. It will be seen that on any criterion there is a substantially lower level of performance when storing and recalling two channels than when storing and

Table 1. Mean number out of ten of totally correct lists

\begin{tabular}{lccc} 
Single Channel & No. & Presented & Double Channel \\
\hline- & & $2 \times 2$ & 8.05 \\
9.3 & 5 & & - \\
7.3 & 6 & $2 \times 3$ & 4.0 \\
3.73 & 7 & & - \\
2.6 & 3 & $2 \times 4$ & 1.82 \\
- & 9 & & - \\
\hline
\end{tabular}

Table 2. Mean number of items correct per list Double Channel Single Channel No. Presented Both Hands Left Hand Right Hand

\begin{tabular}{cccccc}
\hline- & & $2 \times 2$ & 3.56 & 1.78 & 1.78 \\
4.75 & 5 & & - & - & - \\
5.45 & 6 & $2 \times 3$ & 4.16 & 2.02 & 2.14 \\
6.02 & 7 & & - & - & - \\
5.25 & 3 & $2 \times 4$ & 3.81 & 1.96 & 1.85 \\
4.25 & 9 & & - & - & - \\
- & & $2 \times 5$ & 2.24 & 1.25 & 0.98 \\
\hline
\end{tabular}

Table 3. Comparison of single channel performance with one of the two presented in the two channel situation

\begin{tabular}{lccc}
$\begin{array}{l}\text { Single Channel } \\
\text { Probobility of } \\
\text { list totally } \\
\text { correct }\end{array}$ & No. & Presented & $\begin{array}{l}\text { Double Channel } \\
\text { Probability of at } \\
\text { least one chonnel } \\
\text { totally correct }\end{array}$ \\
\hline- & 5 & $2 \times 2$ & 0.845 \\
0.93 & 6 & $2 \times 3$ & - \\
0.31 & 7 & & 0.530 \\
0.73 & 3 & $2 \times 4$ & - \\
0.37 & 9 & & 0.313 \\
0.26 & & $2 \times 5$ & - \\
- & & & 0.034 \\
\hline
\end{tabular}


recalling one channel. It is possible that with intensive practice some improvement may be found, but it seems that we must reject the hypothesis that Ss are capable of handling two lists simultaneously providing the total load does not exceed one immediate memory span. It should be noted that the low levels of performance with two channel presentation are not due to only one of the two channels being processed. Table 3 shows that the probability of correctly processing one channel in the two channel situation is lower than the probability of processing a single channel message of the same length as one of the two channels.

\section{References}

Broadbent, D. E. The role of auditory localisation and attention in memory span. J. exp. Psychol., 1954, 47, 191-196.

Moray, N. Broadbent's filter theory: Postulate $H$ and the problem of switching time. Quart. J. exp. Psychol., 1960, 12, 214-220.

Moray, N., Bates, A., \& Bamett, T. Listening in the 4-eared man. J. Acoust. Soc. Amer., 1965, 38, 196-201.

Moray, N., \& Jordan, A. Practice and compatability in 2-channel short-term memory. Psychon. Sci., 1966, 4, 427-428. 